\title{
Perception of evidence-based practice and the professional environment of Primary Health Care nurses in the Spanish context: a cross-sectional study
}

\author{
Susana González-Torrente ${ }^{1}$, Jordi Pericas-Beltrán², Miguel Bennasar-Veny ${ }^{2 *}$, Rosa Adrover-Barceló , \\ José M. Morales-Asencio ${ }^{3}$ and Joan De Pedro-Gómez ${ }^{2}$
}

\begin{abstract}
Background: The study of the factors that encourage evidence-based clinical practice, such as structure, environment and professional skills, has contributed to an improvement in quality of care. Nevertheless, most of this research has been carried out in a hospital context, neglecting the area of primary health care. The main aim of this work was to assess the factors that influence an evidence-based clinical practice among nursing professionals in Primary Health Care.
\end{abstract}

Methods: A multicentre cross-sectional study was designed, taking the 619 Primary Care staff nurses at the Balearic Islands' Primary Health Care Service, as the study population. The methodology applied consisted on a self-administered survey using the instruments Evidence-Based Practice Questionnaire (EBPQ) and Nursing Work Index (NWI).

Results: Three hundred and seventy seven surveys were received (60.9\% response rate). Self-assessment of skills and knowledge, obtained $66.6 \%$ of the maximum score. The Knowledge/Skills factor obtained the best scores among the staff with shorter professional experience. There was a significant difference in the Attitude factor $(p=0.008)$ in favour of nurses with management functions, as opposed to clinical nurses.

Multivariate analysis showed a significant positive relationship between NWI and level of evidence-based practice $(p<0,0001)$.

Conclusions: Institutions ought to undertake serious reflection on the lack of skills of senior nurses about Evidence-Based Clinical Practice, even when they have more professional experience. Leadership emerge as a key role in the transferral of knowledge into clinical practice.

\section{Background}

Evidence-Based Clinical Practice (EBCP) is known to improve the quality of health care, making it cost-efficient while improving clinical results [1]. But the barriers for transferring research into clinical practice [2-4] challenge this process, which, in their final state, would culminate in what Davis called 'the adoption process' [5].

\footnotetext{
* Correspondence: miquel.bennasar@uib.es

${ }^{2}$ Nursing Department, Evidence Based Clinical Practice and Knowledge Transfer Research Group Members, Balearic Islands University, Carretera de Valldemossa Km 7.5, 07122, Palma, Islas Baleares, Spain

Full list of author information is available at the end of the article
}

Dijkstra (2006) synthesized some barriers and facilitators, as well as interventions, to improve the implementation of new knowledge, identifying that they depend, basically, on factors associated to the professionals, the organisation they work for and their management policies [6]. Grimshaw (1999) and Grol (2001) have already proposed the complexity of the variables involved in the transferral of knowledge into clinical practice $[7,8]$.

It is worrying to observe how, along the route that lies between the production of knowledge and the clinical decision of professionals, there is a progressive

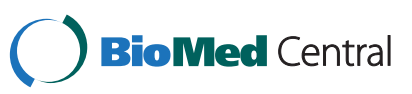


decrease in knowledge, in favour of beliefs, opinions, etc. [9]. Several studies have attempted to analyse this phenomenon from different perspectives, such as the influence of knowledge management $[9,10]$, attitudes, values or training in the process of knowledge transferral into clinical practice [11, 12]. Barriers perceived by professionals concerning the use of research into clinical practice have been studied [13-15], as well as the lack of support of health organisations towards EBCP [16].

Most of the studies conducted on the implementation of EBCP have focused on the area of Hospital Care (HC) $[17-24]$ and frequently on highly specialized units, such as intensive care [25]. The emergence of Magnet Hospitals in USA $[26,27]$ promoted the study of environmental factors that influence nursing practice and the subsequent development of instruments as the Nursing Work Index (PES-NWI) [17, 28, 29].

On the other hand, some questionnaires have been created for analysing factors that promote or prevent evidence based practice, like the Evidence Based Practice Questionnaire (EBPQ) [30]. But there is a paucity of studies analysing these factors in the PHC context, even though the increasing concern about disseminating knowledge in this environment $[14,28,31]$.

In order to diagnose the different elements that influence the impact of organisational climate in nursing practice, Gershon et al. (2004) identified 12 instruments [28], where NWI is one of the most used [32]. This instrument was initially designed by Kramer and Hafner in 1989 [31] and since its initial version, has been refined successively. The most disseminated versions are the one made by Aiken et al (2000) [17], and the PESNWI, validated by Lake (2002), which has shown the greatest explanatory parsimony [33]. In Spain, the NWI-R has been used occasionally, but without a previous validation process $[19,33]$, unlike the PES-NWI, which has undergone a validation process in our context $[34,35]$.

The field of professional skills for EBCP has been less studied and, as a result, existing instruments have been more scarce [36-38] and only a few of them have been validated carefully [38]. In 2006, Upton and Upton reported the EBPQ [30], which has been adapted and validated into the Spanish context $[39,40]$.

The aim of this study was to assess the factors that influence EBCP in the Balearic Islands' Health Service. For this, the objectives of the study were to describe the EBCP patterns in primary health care nurses, the analysis of possible differences related to features of the staff, such gender, age, experience and main practice (management or clinical) and to evaluate the potential influence of the practice environment where they work.

\section{Methods}

\section{Design and setting}

A multicentre cross-sectional study was designed, taking the whole Primary Care staff nurses at the Balearic Islands' Public Health Care Service as the study population. The study was conducted in 2009, among the 619 nurses distributed between 57 health centres $(\mathrm{HC})$.

Nurses received a personalized letter presenting the project and containing the two instruments, along with a request to participate, and a commitment for guarantying anonymity and the compliance with Organic Law 15/1999 on Protection of Details of a Personal Nature. Once answered, the questionnaires were introduced into a closed envelope and handed to the different members of the research team.

Ethical approval for the study was granted by the Balearic Clinical Research Ethical Committee (CEIC-IB). All nurses participating in the study were informed that they could abandon it at any time.

\section{Data collection}

In order to assess the practice environment, we used the NWI questionnaire validated in Spain [41]. The instrument contains 31 items, grouped in 5 factors: 1) Nurse participation in issues related to $H C ; 2)$ Foundation of quality of nursing care; 3) Capacity, leadership and support to nurses by nurse managers; 4) Dimension of nursing staff and adequacy of human resources and 5) Relationship between physicians and nurses.

To assess knowledge, use and attitudes of professionals towards EBCP, we used the EBPQ questionnaire, also validated in Spain [39]. This instrument is made up of 24 items structured in three factors: 1) Practice; 2) Attitude and knowledge; and 3) Skills of professionals in EBCP.

Other variables measured were the professional category (clinical nurses and nurse managers) and number of years in professional service.

\section{Data analysis}

The strategy of analysis comprised an examination of the descriptive data of the sample, bivariate analysis with parametric and non-parametric tests, depending on the nature of the distributions (correlation, ANOVA, Kruskall-Wallis, chi squared). In order to go further into the objective of the study, a multivariate regression model was developed to analyse the effect of the environments on evidence-based practice of professionals. Age, gender, years of professional practice (grouped by $0-2$ years; $>2-10$ years; $>10-20$ years; $>20$ years) and type of practice (clinical or management) and the overall NWI score were taken as independent variables. As a dependent variable, the overall EBPQ score was used. For this analysis, independence was checked using Durbin-Watson statistics, homocedasticity through the association between 
residuals and typified prognosis, normality, using a histogram of typified residuals and linearity, with partial regression graphs.

All analyses were conducted using the statistical package PASW 18.0 and confidence levels were set at $95 \%$ $(\mathrm{p}=0.05)$.

\section{Results}

\section{Respondents}

Of the 619 nurses in primary care practice, 377 responded to the questionnaire $(60.9 \%)$. The respondents consisted of 324 female (86.2\%) and 52 male (13.8\%). The population had a mean professional experience of 20.9 years. The overall mean age was 44.5 years DE: 10.8 (CI 95\% 43.4-45.6). The mean age for men (52) was 43.8 years, DE: 10.6 (CI 95\%: 40.8-46.7) and for women (310) 44.6 years, DE: 10.9 (CI 95\%: 43.4-45.8). Most of them $(98.1 \%)$ held a 3 years Universitary Degree in Nursing, while the remaining $1.9 \%$ had studied an additional Degree in other disciplines.

Three hundred and twenty two (89.2\%) were clinical nurses and 39 (7.9\%) were nurse managers. Concerning to years of experience as nurses, 12 (3.3\%) had been working for less than 2 years; 77 (21.0\%) between 2 and 10 years; 84 (22.9\%) between 10 and 20 years and the remaining 194 (52.9\%), over 20 years.

From this population, $213(56.6 \%)$ had children and $75.4 \%$ of them (72.0\% men and $76.0 \%$ women) lived with a stable partner.

The overall assessment and a breakdown of the different factors (both for the EBPQ and the PES-NWI) can be seen in Table 1 .

\section{Assessment of questionnaires}

Regarding the level of professional competence perceived by nurses in order to develop EBCP (measured with the EBPQ questionnaire) - significant intergroup differences were found in the overall score, depending

Table 1 Assessment of total and different factors in the EBPQ and NWI

\begin{tabular}{lccr}
\hline & Score & DE & \multicolumn{1}{c}{ Cl 95\% } \\
\hline EBPQ total & 112.7 & 20.8 & $(110.6-114.8)$ \\
\hline Practice & 27.7 & 7.5 & $(26.0-28.5)$ \\
\hline Attitude & 21.1 & 3.9 & $(20.7-21.5)$ \\
\hline Knowledge/Skills & 63.9 & 13.3 & $(62.6-65.3)$ \\
\hline NWI total & 80.4 & 15.1 & $(78.9-82.0)$ \\
\hline Participation & 21.7 & 5.7 & $(21.1-22.3)$ \\
\hline Foundation & 26.2 & 5.5 & $(25.7-26.8)$ \\
\hline Management support & 15.6 & 3.8 & $(15.2-16.0)$ \\
\hline Adequate staff & 8.8 & 3.1 & $(8.5-9.1)$ \\
\hline Physician/nurse & 8.1 & 2.4 & $(7.8-8.4)$ \\
\hline
\end{tabular}

377 participants responded to both questionnaires. on the number of years of professional experience $(\mathrm{p}=$ 0.018). With regard to the three factors that make up the EBPQ (Practice, Attitude and Knowledge/Skills), significant differences in the Knowledge/Skills factor were maintained $(\mathrm{p}=0.023)$. It is worth noting that the professionals with shorter experience obtained the best scores (Table 2).

There was a better score for nurses with management functions (supervision and coordination), compared to clinical nurses, in the Attitude factor ( $\mathrm{p}=0.008)$.

The comparison of the PES-NWI among the different strata derived from years of professional experience, showed a significant intergroup difference $(\mathrm{p}<0.027)$ in the Physician/Nurse relationship factor. Despite the lack of statistical significance, a propensity towards obtaining a better score in the groups with lesser experience could be seen, especially in the 0 to 2 years group (Table 3 ).

In the analysis of the overall score according to the type of professional category, nurses who carried out management functions had significantly higher scores $(\mathrm{p}=0.004)$, in three factors: Participation in issues related to the centre, Foundation of quality nursing care and Dimension of nursing staff and adequacy of human resources. No differences were found in the other factors: Capacity, Leadership and Nursing support by nurse managers and Relationships between physicians and nurses (Table 4).

EBPQ and PES-NWI showed no difference among female or male nurses.

Multivariate analysis detected a significant relationship among NWI, years in practice (age was eliminated due to its collinearity with the number of years in practice) and the level of evidence-based practice, with an explanatory capacity of 30\% (Table 5).

\section{Discussion}

The response rate obtained in our study is higher than that obtained in other studies which percentages of $40 \%$ [42] or even lower [43]. However, they are very similar, as far as the proportion of men and women (1 man for every 6 women) and the mean age of the nurses surveyed (over 40 years) is concerned. Regarding the professional experience (mean $=20.9$ years) our study obtains similar figures to those achieved by Gerrish et al. (2011) in England [43], but, on the whole, they are higher than those in other similar studies carried out in the United States, where the mean number of years worked is 10 $[42,44]$. With respect to the academic level it is difficult to compare with other countries like the United Kingdom, United States or Canada, where most of the studies have been conducted and nurses have a long tradition in professional development, including the possibility of access to a doctorate. 
Table 2 Assessment of the total EBPQ and of its factors according to the different groups of number of years in professional practice

\begin{tabular}{|c|c|c|c|c|c|}
\hline \multirow[t]{2}{*}{ Factor $(\text { Vmax })^{a}$} & \multirow[t]{2}{*}{ Mean } & \multicolumn{2}{|c|}{$\mathrm{Cl}$ at $95 \%$} & \multirow[t]{2}{*}{$\mathrm{DE}$} & \multirow[t]{2}{*}{$p$} \\
\hline & & Lower limit & Upper limit & & \\
\hline \multicolumn{6}{|l|}{ Practice (42) } \\
\hline Intergroups & 27.6 & 26.8 & 28.4 & 7.5 & 0.065 \\
\hline 0 to 2 years & 32.7 & 29.8 & 35.6 & 4.6 & \\
\hline 2 to 10 years & 28.3 & 26.9 & 29.7 & 6.1 & \\
\hline 10 to 20 years & 26.9 & 24.9 & 28.8 & 8.9 & \\
\hline$>20$ years & 27.3 & 26.3 & 28.4 & 7.5 & \\
\hline \multicolumn{6}{|l|}{ Attitude (28) } \\
\hline Intergroups & 21.0 & 20.6 & 21.5 & 4.0 & 0.094 \\
\hline 0 to 2 years & 22.3 & 20.1 & 24.5 & 3.5 & \\
\hline 2 to 10 years & 21.2 & 20.4 & 22.0 & 3.7 & \\
\hline 10 to 20 years & 21.8 & 21.0 & 22.5 & 3.5 & \\
\hline$>20$ years & 20.6 & 20.0 & 21.2 & 4.2 & \\
\hline \multicolumn{6}{|c|}{ Knowledge/Skills (98) } \\
\hline Intergroups & 63.8 & 62.5 & 65.2 & 13,4 & 0,023 \\
\hline 0 to 2 years & 72.3 & 66.4 & 78.2 & 9,3 & \\
\hline 2 to 10 years & 66.1 & 63.1 & 69.2 & 13,5 & \\
\hline 10 to 20 years & 63.9 & 61.4 & 66.5 & 11,9 & \\
\hline$>20$ years & 62.4 & 60.4 & 64.33 & 13,9 & \\
\hline \multicolumn{6}{|l|}{ EBPQ total (168) } \\
\hline Intergroup & 112.5 & 110.3 & 114.6 & 20.8 & 0.018 \\
\hline 0 to 2 years & 127.3 & 117.4 & 137.0 & 15.4 & \\
\hline 2 to 10 years & 115.6 & 111.1 & 120.1 & 19.8 & \\
\hline 10 to 20 years & 112.5 & 108.2 & 116.9 & 20.1 & \\
\hline$>20$ years & 110.3 & 107.3 & 113.3 & 21.3 & \\
\hline
\end{tabular}

Anova factor test was applied.

${ }^{a} V$ max: maximum value of the factor of the questionnaire.

In relation to the results of the EBPQ questionnaire, we observed some remarkable results, as the higher scores obtained among nurses with shorter professional experience. Thus, the group that obtains the highest score is the one made up of nurses in their first two years of clinical practice, and the one that obtains the lowest score is the group 10-20 years. These data point out the existence of a paradoxical and deep perception of lack of competence with respect to the use of EBCP, among experienced nurses. This result mismatches with other studies conducted outside Spain using EBPQ, where the greater the number of years of experience, the higher the score obtained by nurses in the Daily practice factor [42], or no significant differences were observed [45].

These contradictory results could be explained by three factors: the lack of a professional career which encourages nurses to make progress on their own development, the absence of specialisation in Community Nursing in Spain until recently, and the common fact in all the Spanish territory of highly experienced hospital nurses moving to Primary Health Care to conclude the end stage of their professional career in this context, where they are not expert.

Perhaps, the youngest nurses tend to consider themselves more capable for developing EBCP because of their recent university experience, where these issues are studied, and the continuation of relations with Faculty staff that could support them in the processes of seeking and interpretation of evidence [46].

With respect to the significant difference in the Attitude factor of the EBPQ in favour of nurses with management functions as opposed to clinical ones, this could be due to the greater commitment and motivation of nurses who accept to perform as nursing coordinators in health centres. Despite this position has few rewards, it is generally accepted by nurses with a high degree of professional development [47].

The NWI factor which obtains the highest score is Management support ( $78 \%$ of the possible maximum score), reflecting that nurses consider the support from nursing coordinators a key factor in achieving the objectives 
Table 3 Assessment of the total NWI and of its factors according to the different groups of number of years in professional practice

\begin{tabular}{|c|c|c|c|c|c|}
\hline \multirow[t]{2}{*}{ Factor $(\text { Vmax })^{a}$} & \multirow[t]{2}{*}{ Mean } & \multicolumn{2}{|c|}{$\mathrm{Cl}$ al $95 \%$} & \multirow[t]{2}{*}{$\mathrm{DE}$} & \multirow[t]{2}{*}{$p$} \\
\hline & & Lower limit & Upper limit & & \\
\hline \multicolumn{6}{|l|}{ Participation (36) } \\
\hline Intergroup & 21.6 & 21.0 & 22.2 & 5.7 & 0.657 \\
\hline 0 to 2 years & 23.3 & 20.3 & 26.4 & 4.8 & \\
\hline 2 to 10 years & 22.0 & 20.7 & 23.4 & 6.1 & \\
\hline 10 to 20 years & 21.5 & 20.4 & 22.7 & 5.4 & \\
\hline$>20$ years & 21.4 & 21.1 & 22.3 & 5.8 & \\
\hline \multicolumn{6}{|l|}{ Foundation (40) } \\
\hline Intergroup & 26.1 & 25.6 & 26.7 & 5.5 & 0.157 \\
\hline 0 to 2 years & 29.3 & 26.0 & 32.5 & 5.1 & \\
\hline 2 to 10 years & 26.2 & 24.9 & 27.5 & 5.7 & \\
\hline 10 to 20 years & 25.5 & 24.3 & 26.6 & 5.4 & \\
\hline$>20$ years & 26.2 & 25.4 & 27.0 & 5.4 & \\
\hline \multicolumn{6}{|c|}{ Manager support (20) } \\
\hline Intergroup & 15.5 & 15.1 & 15.9 & 3.8 & 0.260 \\
\hline 0 to 2 years & 16.1 & 13.3 & 18.9 & 4.4 & \\
\hline 2 to 10 years & 16.2 & 15.4 & 17.0 & 3.5 & \\
\hline 10 to 20 years & 15.6 & 14.8 & 16.4 & 3.6 & \\
\hline$>20$ years & 15.2 & 14.6 & 15.8 & 4.0 & \\
\hline \multicolumn{6}{|c|}{ Adequacy of staff (16) } \\
\hline Intergroup & 8.8 & 8.4 & 9.1 & 3.2 & 0.777 \\
\hline 0 to 2 years & 8.8 & 7.2 & 10.3 & 2.5 & \\
\hline 2 to 10 years & 8.4 & 7.8 & 9.1 & 2.9 & \\
\hline 10 to 20 years & 8.8 & 8.1 & 9.4 & 3.1 & \\
\hline$>20$ years & 8.9 & 8.4 & 9.4 & 3.3 & \\
\hline \multicolumn{6}{|c|}{ Physician/nurse relationship (12) } \\
\hline Intergroup & 8.1 & 7.9 & 8.4 & 2.4 & 0.027 \\
\hline 0 to 2 years & 8.3 & 7.9 & 10.6 & 2.2 & \\
\hline 2 to 10 years & 8.2 & 7.6 & 8.7 & 2.4 & \\
\hline 10 to 20 years & 8.6 & 8.1 & 9.1 & 2.3 & \\
\hline$>20$ years & 7.8 & 7.5 & 8.1 & 2.4 & \\
\hline \multicolumn{6}{|l|}{ NWI total (124) } \\
\hline Intergroup & 80.2 & 78.6 & 81.7 & 15.0 & 0.415 \\
\hline 0 to 2 years & 86.7 & 78.3 & 95.0 & 13.2 & \\
\hline 2 to 10 years & 80.1 & 77.8 & 84.2 & 14.1 & \\
\hline 10 to 20 years & 79.9 & 76.7 & 83.2 & 15.0 & \\
\hline$>20$ years & 79.5 & 77.3 & 81.7 & 15.4 & \\
\hline
\end{tabular}

Anova factor test was applied.

${ }^{a}$ Vmax: maximum value of the factor of the questionnaire.

related to EBCP. Several studies have identified managers, not only as a key factor for the generation and implementation of EBCP, but also for the creation of a good research environment [48-50]. In other studies, nurses have declared the need for a mentor to guide them along the search and implementation of evidence [45, 46, 49]. Shirey (2006), in reference to the creation of magnet Hospitals, states the key role of leadership and how it can be fostered with appropriate training [49]. In this respect, there are several publications concerning experiences of EBCP implementation based on teaching and training nurse coordinators $[48,50,51]$.

Also, in the PES-NWI factor Foundation of quality nursing care, there is a significant difference in favour of nurse managers. Gerrish et al. (2011), in a study carried out among 855 hospital and primary health care nurses 
Table 4 Assessment of the total NWI and of its factors according to professional category

\begin{tabular}{|c|c|c|c|c|c|}
\hline \multirow[t]{2}{*}{ Factor $(\text { Vmax })^{a}$} & \multirow[t]{2}{*}{ Mean } & \multicolumn{2}{|c|}{ IC al $95 \%$} & \multirow[t]{2}{*}{$\mathrm{DE}$} & \multirow[t]{2}{*}{$p$} \\
\hline & & Lower limit & Upper limit & & \\
\hline \multicolumn{6}{|l|}{ Participation (36) } \\
\hline Clinical nurse & 21.3 & 20.6 & 21.9 & 5.7 & \multirow[t]{2}{*}{0.00} \\
\hline Nurse manager & 24.5 & 23.0 & 26.1 & 4.9 & \\
\hline \multicolumn{6}{|l|}{ Foundation (40) } \\
\hline Clinical nurse & 25.9 & 25.2 & 26.5 & 5.6 & \multirow[t]{2}{*}{0.010} \\
\hline Nurse manager & 28.3 & 26.9 & 29.7 & 4.4 & \\
\hline \multicolumn{6}{|c|}{ Manager support (20) } \\
\hline Clinical nurse & 15.4 & 15.0 & 15.9 & 3.9 & \multirow[t]{2}{*}{0.116} \\
\hline Nurse manager & 16.5 & 15.7 & 17.3 & 2.5 & \\
\hline \multicolumn{6}{|c|}{ Adequacy of staff (16) } \\
\hline Clinical nurse & 8.7 & 8.3 & 9.0 & 3.2 & \multirow[t]{2}{*}{0.037} \\
\hline Nurse manager & 9.8 & 8.7 & 10.8 & 3.3 & \\
\hline \multicolumn{6}{|c|}{ Physician/nurse relationship (12) } \\
\hline Clinical nurse & 8.2 & 7.9 & 8.4 & 2.4 & \multirow[t]{2}{*}{0.30} \\
\hline Nurse manager & 7.7 & 7.0 & 8.5 & 2.2 & \\
\hline \multicolumn{6}{|l|}{ NWI total (124) } \\
\hline Clinical nurse & 79.4 & 77.7 & 81.0 & 15.2 & \multirow[t]{2}{*}{0.004} \\
\hline Nurse manager & 86.8 & 82.9 & 90.7 & 11.9 & \\
\hline
\end{tabular}

322 clinical nurses and 39 nurse managers responded validly.

${ }^{a} V$ max: maximum value of the factor of the questionnaire.

in England to implement EBCP in their environments, consider that holding a master degree would be recommended for those nurses who lead the implementation process [43]. Therefore, it is patent the essential role of leadership in the process of implementation evidence into clinical practice [52].

In the light of the NWI results in the Participation factor, the nurses in our study seem to feel that they are not too involved in issues concerning the centre, although once again, the managers score higher in this factor. As afore mentioned, it is of vital importance for the generation and implementation of EBN to create a work environment that encourage the participation and involvement of all nurses in providing evidence-based quality care [53, 54]. Kramer and Schmalenberg (2008), stated that in magnet hospitals, (where a good working environment encourages nursing staff recruitment and quality of care), what managers understand as a good working environment is not necessarily the same for the nursing staff [55]. We believe that this clarification is also applicable to the implementation of EBCP into PHC.

It seems realistic, given the structure of our PHC organisations, that nursing coordinators and managers feel more involved in the organisation than other nurses. This may be influenced by the fact that the design of information flow is pyramidal, and nursing coordinators have prior access to information, or they are frequently consulted about possible changes, and they are the ones who transmit this to the staff in their HC. In this same sense, there is a relevant study conducted in the Community of Madrid in which a generalised complaint concerning poor feedback by management to different PHC teams, reports how aims and priorities are not clear, teams are rarely informed about the expectations that

Table 5 Multivariate analysis

\begin{tabular}{|c|c|c|c|c|c|}
\hline & \multirow{2}{*}{$\begin{array}{l}\text { Non-standard } \\
\text { coefficients }\end{array}$} & \multirow{2}{*}{$\begin{array}{c}\text { Typified } \\
\text { coefficients }\end{array}$} & \multirow[t]{2}{*}{ Sig } & \multicolumn{2}{|c|}{$\mathrm{Cl} 95 \%$} \\
\hline & & & & Lower limit & Upper limit \\
\hline (Constant) & 77.050 & & 0.000 & 57.284 & 96.816 \\
\hline NWI total & 0.337 & 0.236 & 0.000 & 0.188 & 0.487 \\
\hline Gender & -2.302 & -0.039 & 0.460 & -8.428 & 3.824 \\
\hline Category & 1.171 & 0.036 & 0.491 & -2.170 & 4.512 \\
\hline Years of practice & -0.733 & -0.377 & 0.004 & -1.230 & -0.236 \\
\hline
\end{tabular}

Multiple regression was carried out with the EBPQ as a dependent variable and the ones in the first column as predictor variables. 
are set and managers do not support, recognize or show enough gratitude for the good work carried out by the teams [56].

In the NWI, the total Adequacy of the staff factor obtains $55 \%$ of the maximum score, although compared with the rest of the factors it is the lowest valued one. The ratio of nurses per population in Spain is below the European standard [57]. It is well known that a shortage of nurses creates a loop of job dissatisfaction due to work overload, which results in a worse quality of care provided and it is an important barrier for implementing EBCP $[44,54]$. In studies conducted in the Spanish PHC environment, the need for training and adequacy of staff dimension is highlighted, emphasizing the imbalance between nursing staff and GPs, with poorer figures in nurses. Moreover, references are made to the health system working badly, by creating new positions and responsibilities for PHC without providing the parallel means to put them into practice, thus creating bad feeling between professionals and increasing stress $[56,57]$. Besides, Sancho-Viudes et al. (2002) in the PHC environment in Mallorca identified - as problems to be solved the poor adequacy of staff dimension compared to the population to be cared for, the need for updating clinical guides and protocols, the lack of specific training in community nursing, and the subsequent need for a specialization in community nursing [47]. Kramer and Schmalenberg (2008), when they describe the requirements that must be met in order to generate a good climate in the work place, point out the perception of staff adequacy [55]. This difference in perception between nurse managers and staff nurses should alert us to the fact that managers may be slightly isolated from their nurses and their daily reality.

Squires et al. (2011) in a recent review concludes that, in all the studies examined, the attitude of nurses towards research is the only individual characteristic that is positively related to the use of research at work, although carrying out clinical sessions in the workplace, having higher qualifications, a professional career, a clinical specialization or a high job satisfaction are also important [58]. Even though the resolution of potential barriers that hinder EBCP is a necessary condition, this could be not enough to succeed, as other less objective or measurable factors such as values, motivation, environment or empathy are just as important or even more than the former [59]. A recent review carried out by Solomons and Spross (2011) concludes that many of the measurement scales used in the studies do not measure these aspects [60]. In another recent study, Levin piloted an EBCP implementation model among home visiting nurses in New York which took into account their beliefs regarding EBCP, group cohesion, productivity, job satisfaction and burnout due to staff changes, relating a greater implementation of EBCP with lower burnout and greater satisfaction with the work group [61].

\section{Conclusion}

The findings from this study highlight the importance of organisational culture and context in achieving EBCP. This problem affects the relationships between institutions and nurses throughout many countries, as it is reflected in the literature, and it has been also corroborated in this study carried out in Spain.

The commitment of nurses and health managers at the highest level is required to promote a change in achieving EBCP, to assure the highest level of competence and effectiveness which should lead to improved patient outcomes.

It would be worth thinking about the need to create a nursing research friendly work environment, supportive towards knowledge transfer, by putting into practice what some authors call a culture change, which would involve an increase in communication and collaboration in both organisational and clinical decision making, a more active attitude towards research in the work place, and a change in attitudes and beliefs.

Furthermore, it would be highly desirable to improve the leadership skills for nurse coordinators, as they appear to be key agents in the implementation of a culture more favourable towards EBCP. On the other hand, these strategies should involve the whole PHC team, always taking into account the characteristics of the nurses, in such a way that they feel they are contributing and are useful, above all with highly experienced nurses, because of their key role in implementing EBCP.

\section{Limitations}

This study has some limitations. It is a cross-sectional design that does not allow us to explore the directionality of the associations and, on the other hand, elements such as leadership - which appear to bear increasingly more weight in the adoption of evidence by professionals - have been explored tangentially. Moreover, in the sampling process, there was an under-representation of the group of professionals with 0 to 2 years' experience, with $14 \%$ under the expected with respect to the size of this stratum in the different centres. This selection bias might have been caused by the selection criteria in order to respond to the survey, which excluded professionals with less than 6 months in their work place, and these nurses had worked mainly on short-term contracts and there are more job perspectives for novel nurses in hospitals than in PHC.

Balearic Islands is a geographically isolated territory and it is plausible that an own culture could determine some of these findings. Therefore, the generalisation of these results should be made carefully to other communities. 


\section{Competing interests}

All authors declare no competing interests.

\section{Author's contributions}

SGT was involved in the study conception and design, drafting and conducting the surveys among nurses. JPB was involved in the study conception and design, drafting and conducting the surveys among nurses. MBV and JMMA were involved in the study design as well as in drafting and critical revision of the manuscript. RAB was involved in the study conception and design and conducting the surveys among nurses. JDPG was involved in the study conception and design, drafting and critical revision of the critical revision of the manuscript. RAB was involved in the study conception and design and conducting the surveys among nurses. JDPG was involved in the study conception and design, drafting and critical revision of the manuscript, supervision and statistical analysis. All authors read and approved the final manuscript.

\section{Funding}

This article is part of a research project financed by the Health Research Fund (PI 09/90512. Health Ministry) following a rigorous peer-reviewed funding process.

\section{Acknowledgments}

The authors would like to thank Balearic Islands Public Health Service for their involvement and collaboration.

\section{Author details}

${ }^{1}$ Primary Health Care, Balearic Islands Health Service, Spain. ${ }^{2}$ Nursing Department, Evidence Based Clinical Practice and Knowledge Transfer Research Group Members, Balearic Islands University, Carretera de Valldemossa Km 7.5, 07122, Palma, Islas Baleares, Spain. ${ }^{3}$ Faculty of Health Sciences, University of Málaga, Málaga, Spain.

Received: 12 October 2011 Accepted: 17 July 2012

Published: 31 July 2012

\section{References}

1. Aiken LH, Clarke SP, Sloane DM, Lake ET, Cheney T: Effects of hospital care environment on patient mortality and nurse outcomes. J Nurs Adm 2008, 38(5):223-229.

2. Cummings GG, Estabrooks CA, Midodzi WK, Wallin L, Hayduk L: Influence of organizational characteristics and context on research utilization. Nurs Res 2007, 56(4 Suppl):S24-S39.

3. Estabrooks CA, Midodzi WK, Cummings GG, Wallin L: Predicting research use in nursing organizations: a multilevel analysis. Nurs Res 2007, 56(4 Suppl):S7-S23.

4. Wallin L: Knowledge translation and implementation research in nursing. Int J Nurs Stud 2009, 46(4):576-587.

5. Davis DA, Taylor-Vaisey A: Translating guidelines into practice: a systematic review of theoretic concepts, practical experience and research evidence in the adoption of clinical practice guidelines. Can Med Assoc J 1997, 157(4):408-416.

6. Dijkstra R, Wensing M, Thomas R, Akkermans R, Braspenning J, Grimshaw J, Grol $R$ : The relationship between organisational characteristics and the effects of clinical guidelines on medical performance in hospitals, a meta-analysis. BMC Health Serv Res 2006, 6(1):53.

7. Grimshaw J: Getting evidence into practice. Eff Health Care 1999, 5(1):1-16.

8. Grol R: Successes and failures in the implementation of evidence-based guidelines for clinical practice. Med Care 2001, 39(8 Suppl 2):||46-||54.

9. Glasziou $P$, Haynes B: The paths from research to improved health outcomes. ACP J Club 2005, 142(2):A8-A10.

10. Thompson C, McCaughan D, Cullum N, Sheldon TA, Mulhall A, Thompson DR: Research information in nurses' clinical decision-making: what is useful? J Adv Nurs 2001, 36(3):376-388.

11. Klein R: The NHS and the new scientism: solution or delusion? QJM 1996, 89(1):85-87.

12. Peiró $S$, Bernal E: ¿ A qué incentivos responde la utilización hospitalaria en el Sistema Nacional de Salud. Gac Sanit/SESPAS 2006, 20(Supl 1):110-116.

13. Bryar RM, Closs SJ, Baum G, Cooke J, Griffiths J, Hostick T, Kelly S, Knight S, Marshall K, Thompson DR: The Yorkshire BARRIERS project: diagnostic analysis of barriers to research utilisation. Int J Nurs Stud 2003, 40(1):73-84

14. McKenna HP, Ashton S, Keeney S: Barriers to evidence-based practice in primary care. J Adv Nurs 2004, 45(2):178-189.

15. Nolan M, Morgan L, Curran M, Clayton J, Gerrish K, Parker K: Evidence-based care: can we overcome the barriers? Br J Nurs 1998, 7(20):1273-1278

16. De Pedro Gómez JE, Morales Asencio JM: Las organizaciones ¿favorecen o dificultan una práctica enfermera basada en la evidencia? Index Enferm 2004, 13:26-31.

17. Aiken LH, Patrician PA: Measuring organizational traits of hospitals: the Revised Nursing Work Index. Nurs Res 2000, 49(3):146-153.

18. Estabrooks CA, Tourangeau AE, Humphrey CK, Hesketh KL, Giovannetti $P$, Thomson D, Wong J, Acorn S, Clarke H, Shamian J: Measuring the hospital practice environment: a Canadian context. Res Nurs Health 2002 25(4):256-268.

19. Juvé Udina ME, Farrero Muñoz S, Monterde Prat D, Hernández Villen O, Sistac Robles M, Rodríguez Cala A, Quilez Castillo F, Suñer Soler R, Arbués Visús MT, Martín Al: Analysis of an organisational context in nursing practice. The Nursing Work Index in public hospitals [Spanish]. Metas Enferm 2007, 10(7):67-73.

20. Kramer M, Schmalenberg C: The Practice of Clinical Autonomy in Hospitals: 20000 Nurses Tell Their Story. Crit Care Nurse 2008, 28(6):58-71.

21. Lucero RJ, Lake ET, Aiken LH: Variations in nursing care quality across hospitals. J Adv Nurs 2009, 65(11):2299-2310.

22. Needleman J, Buerhaus P, Mattke S, Stewart M, Zelevinsky K: Nurse-staffing levels and the quality of care in hospitals. N Engl J Med 2002, 346(22):1715-1722

23. Van Bogaert P, Meulemans H, Clarke S, Vermeyen K, Van de Heyning P: Hospital nurse practice environment, burnout, job outcomes and quality of care: test of a structural equation model. J Adv Nurs 2009, 65(10):2175-2185.

24. de Pedro-Gomez J, Morales-Asencio JM, Sese Abad A, Bennasar Veny M, Artigues Vives G, Perello Campaner C: Nursing practice settings and competence to incorporate evidence into decisions: analysis of the situation in the Balearic Islands (Spain). Gac Sanit/SESPAS 2011, 25(3):191-197.

25. Schmalenberg C, Kramer M: Types of intensive care units with the healthiest, most productive work environments. Am J Crit Care 2007, 16 (5):458-468. quiz 469.

26. Kramer M, Schmalenberg C: Magnet hospitals: Part II. Institutions of excellence. J Nurs Adm 1988, 18(2):11-19.

27. Kramer M, Schmalenberg C: Magnet hospitals: Part I. Institutions of excellence. J Nurs Adm 1988, 18(1):13-24.

28. Gershon RR, Stone PW, Bakken S, Larson E: Measurement of organizational culture and climate in healthcare. J Nurs Adm 2004, 34(1):33-40.

29. Thompson C, McCaughan D, Cullum N, Sheldon T, Raynor P: Barriers to evidence-based practice in primary care nursing-why viewing decision-making as context is helpful. J Adv Nurs 2005, 52(4):432-444.

30. Upton D, Upton P: Development of an evidence-based practice questionnaire for nurses. J Adv Nurs 2006, 53(4):454-458.

31. Kramer M, Hafner LP: Shared values: impact on staff nurse job satisfaction and perceived productivity. Nurs Res 1989, 38(3):172-177.

32. Gershon RRM, Stone PW, Zeltser M, Faucett J, Macdavitt K, Chou S-S: Organizational Climate and Nurse Health Outcomes in the United States: A Systematic Review. Ind Health 2007, 45(5):622-636.

33. Lake ET: Development of the practice environment scale of the Nursing Work Index. Res Nurs Health 2002, 25(3):176-188.

34. López-Alonso S: Estudio piloto para la validación de una escala sobre el entorno de práctica enfermera en el Hospital San Cecilio. Enferm Clín 2005, 15(1):8-16.

35. De Pedro-Gomez J, Morales-Asencio JM, Sese-Abad A, Bennasar-Veny M, Pericas-Beltran J, Miguelez-Chamorro A: Psychometric testing of the Spanish version of the practice environment scale of the nursing work index in a primary healthcare context. J Adv Nurs 2012, 68(1):212-221.

36. Fritsche L, Greenhalgh T, Falck-Ytter Y, Neumayer HH, Kunz R: Do short courses in evidence based medicine improve knowledge and skills? Validation of Berlin questionnaire and before and after study of courses in evidence based medicine. BMJ 2002, 325(7376):1338-1341.

37. Ramos KD, Schafer S, Tracz SM: Validation of the Fresno test of competence in evidence based medicine. BMJ 2003, 326(7384):319-321. 
38. Shaneyfelt T, Baum KD, Bell D, Feldstein D, Houston TK, Kaatz S, Whelan C, Green M: Instruments for evaluating education in evidence-based practice: a systematic review. JAMA 2006, 296(9):1116-1127.

39. De Pedro Gómez J, Morales-Asencio JM, Sesé Abad A, Bennasar Veny M, Ruiz Roman MJ, Muñoz Ronda F: Validación de la versión española del cuestionario sobre la práctica basada en la evidencia en enfermería. Rev Esp Salud Publica 2009, 83:577-586.

40. De Pedro-Gomez J, Morales-Asencio JM, Bennasar-Veny M, Artigues-Vives G, Perello-Campaner C, Gomez-Picard P: Determining factors in evidencebased clinical practice among hospital and primary care nursing staff. J Adv Nurs 2012, 68(2):452-459.

41. De Pedro Gómez J, Morales-Asencio JM, Sesé Abad A, Bennasar Veny M, Artigues Vives G, Pericàs Beltrán J: Validación y adaptación al español de la escala del entorno de práctica enfermera del Nursing Work Index. Metas Enferm 2009, 12(7):65-73.

42. Koehn ML, Lehman K: Nurses' perceptions of evidence-based nursing practice. J Adv Nurs 2008, 62(2):209-215.

43. Gerrish K, Guillaume L, Kirshbaum M, McDonnell A, Tod A, Nolan M: Factors influencing the contribution of advanced practice nurses to promoting evidence-based practice among front-line nurses: findings from a cross-sectional survey. J Adv Nurs 2011, 67(5):1079-1090.

44. Meraviglia M, Grobe SJ, Tabone S, Wainwright M, Shelton S, Miner H, Jordan C: Creating a positive work environment: implementation of the nurse-friendly hospital criteria. J Nurs Adm 2009, 39(2):64-70.

45. Brown CE, Wickline MA, Ecoff L, Glaser D: Nursing practice, knowledge, attitudes and perceived barriers to evidence-based practice at an academic medical center. J Adv Nurs 2009, 65(2):371-381.

46. Melnyk BM, Fineout-Overholt E, Fischbeck Feinstein N, Li H, Small L, Wilcox $L$, Kraus R: Nurses' perceived knowledge, beliefs, skills, and needs regarding evidence-based practice: implications for accelerating the paradigm shift. Worldviews Evid Based Nurs / Sigma Theta Tau Int Honor Soc Nurs 2004, 1(3):185-193.

47. Sancho Viudes S, Vidal Thomàs C, Cañellas Pons R, Caldés Pinilla MJ, Corcoll Reixach J, Ramos Montserrat M: Current status analysis and suggestions for improvement in primary care nursing in Mallorca, Spain: a research with focal groups. Rev Esp Salud Publica 2002, 76:531-543.

48. Alleyne J, Jumaa MO: Building the capacity for evidence-based clinical nursing leadership: the role of executive co-coaching and group clinical supervision for quality patient services. J Nurs Manag 2007, 15(2):230-243.

49. Shirey MR: Authentic leaders creating healthy work environments for nursing practice. Am J Crit Care 2006, 15(3):256-267.

50. Strout TD, Lancaster K, Schultz AA: Development and implementation of an inductive model for evidence-based practice: A grassroots approach for building evidence-based practice capacity in staff nurses. Nurs Clin North Am 2009, 44(1):93-102. xi.

51. Jasper M, Jumaa M: Leadership for Evidence-Based Practice, in Effective Healthcare Leadership. Oxford: Blackwell Publishing Ltd; 2008.

52. Kurtzman ET, Corrigan JM: Measuring the contribution of nursing to quality, patient safety, and health care outcomes. Policy Polit Nurs Pract 2007, 8(1):20-36

53. Calarco MM: The impact of positive practices on nurse work environments: emerging applications of positive organizational scholarship. West J Nurs Res 2010, 33(3):365-384

54. Middleton S, Griffiths R, Fernandez R, Smith B: Nursing practice environment: How does one Australian hospital compare with magnet hospitals? Int J Nurs Pract 2008, 14(5):366-372.

55. Kramer $M$, Schmalenberg C: Confirmation of a healthy work environment. Crit Care Nurse 2008, 28(2):56-63. quiz 64.

56. Conde F: Investigación sobre las necesidades de salud de la población de Vallecas Conclusiones de la $1^{\text {a }}$ fase de la investigación./nstituto de Salud Publica de Madrid; 2003. Internet-delivered report available in:http:// www.madrid.org/cs/Satellite?blobcol=urldata\&blobheader= application\%2Fpdf\&blobheadername1=Contentdisposition\&blobheadername2=cadena\&blobheadervalue 1= filename\%3D40+Necesidades+de+Salud+de+la+Poblaci\%C3\%B3n+ de+Vallecas.pdf\&blobheadervalue2=language\%3Des\%26site\% 3DPortalSalud\&blobkey=id\&blobtable=MungoBlobs\&blobwhere $=$ 1202779048779\&ssbinary=true.

57. Hernández JF: La enfermería frente al espejo: mitos y realidades. F Alternativas; 2010. http://www.falternativas.org/content/download/16183/ 461362/version/1/file/doc162.pdf.
58. Squires JE, Estabrooks CA, Gustavsson P, Wallin L: Individual determinants of research utilization by nurses: a systematic review update. Implement Sci 2011, 6:1.

59. Brown CE, Ecoff L, Kim SC, Wickline MA, Rose B, Klimpel K, Glaser D: Multi-institutional study of barriers to research utilisation and evidence-based practice among hospital nurses. J Clin Nurs 2010, 19(13-14):1944-1951.

60. Solomons NM, Spross JA: Evidence-based practice barriers and facilitators from a continuous quality improvement perspective: an integrative review. J Nurs Manag 2011, 19(1):109-120.

61. Levin RF, Fineout-Overholt E, Melnyk BM, Barnes M, Vetter MJ: Fostering evidence-based practice to improve nurse and cost outcomes in a community health setting: a pilot test of the advancing research and clinical practice through close collaboration model. Nurs Adm Q 2011, 35(1):21-33.

doi:10.1186/1472-6963-12-227

Cite this article as: González-Torrente et al:: Perception of evidencebased practice and the professional environment of Primary Health Care nurses in the Spanish context: a cross-sectional study. BMC Health Services Research 2012 12:227.

\section{Submit your next manuscript to BioMed Central and take full advantage of:}

- Convenient online submission

- Thorough peer review

- No space constraints or color figure charges

- Immediate publication on acceptance

- Inclusion in PubMed, CAS, Scopus and Google Scholar

- Research which is freely available for redistribution

Submit your manuscript at www.biomedcentral.com/submit
C) Biomed Central 